\title{
Exploration and Analysis on Construction Technology of Wind Farms in Arctic Region
}

\author{
Chunhua Hu, Yongjun Xia, Jiancheng Wan and Zeming Song \\ China Electric Power Research Institute
}

\begin{abstract}
Keywords: Arctic region, onshore wind farms, offshore wind farms, construction technology
Abstract: This paper discusses in detail the characteristics of the Arctic region environment and the difficulties in constructing wind farms there. Considering the characteristics of the Arctic region environment, the paper analyzes major construction works such as material transportation, foundation construction and wind turbine installation in offshore wind farm construction in the Arctic region and offers feasible solutions and technology programs.
\end{abstract}

\section{Introduction}

The Arctic region is rich in wind resources, but cold weather and harsh environment are also its characteristics. How to develop and construct wind power in Arctic region is still a new topic. Low temperatures, frequent blizzards, remote location, lack of infrastructure and marine environmental data and sensitive ecological environment pose many difficulties in the construction of wind farms there. Different from environments of low latitudes, the Arctic region entails such problems as long route, high costs of logistics, and ecological environment that is vulnerable to damage but difficult to restore. The coldness will impose difficulty in operating the construction platform, prevent the equipment from safe bearing and normal operation, and put the construction equipment prone to brittle fracture and under higher requirement on fatigue strength. Therefore, the study of wind power construction technology in the Arctic region is a new and valuable subject and can provide valuable scientific reference for development and utilization of new energy in the Arctic region.

\section{Environmental Characteristic on Affecting Wind Farm Construction in Arctic Region}

Low Temperature.The weather in the Arctic region is cold, with a winter that lasts up to nine months under temperatures as low as $-50^{\circ} \mathrm{C}$. The annual average ground temperature of permafrost is as low as -10 to $-5^{\circ} \mathrm{C}$. The highest average temperature, which is in August, is only $-8^{\circ} \mathrm{C}$. In the Arctic region, the winter, which lasts up to nine months, is a highly important construction season, especially for linear projects. If the construction is only done in warm seasons, it would not be economic and efficient. The severely cold temperatures in the Arctic region adversely affect the wind power construction there.

Windy Conditions.Wind farms are generally construct in areas with good wind resources, and the lifting of equipment during inland wind farm construction may inevitably encounter windy weather. The greater wind in the Arctic region than the inland can affect the lifting of equipment more significantly.

Icy Conditions.The Arctic region is covered by ice which can damage electrical equipment when it falls on the equipment and makes it damp while it is running. Workers may fall of the slippery equipment due to ice. The ground of Arctic region is mostly permafrost, or covered by snow or even ice. If the machinery has to walk on a slope, sideslip is likely to occur. Workers who operate for a 
long time in icy environment are prone to "snow blindness" due to white ice that irritates eyes. The ice can also seriously affect vehicles. Due to ice or snow, the running vehicles may be faced with such risks as brake failure or sideslip.

Permafrost.The construction activity itself can greatly disturb permafrost, moving down the upper limit of permafrost and leading to increased permafrost temperature and melted underground ice, which further causes changes in the nature of engineering and deformation and damage of foundation in permafrost regions. These results would affect the stability of foundation and impose difficulties in construction and operation. To ensure the safety of construction works and operation, various measures must be taken during the construction process to reduce or eliminate the construction disturbance to permafrost and address the impact of permafrost thaw settlement and frost heave on the foundation.

\section{Research on Construction Technology of Offshore Wind Farms in Arctic Region}

Offshore wind farms in the Arctic region are still in the exploratory stage and so far there is no example of offshore wind farm construction in the Arctic region. Due to the restrictions of climate and equipment, offshore wind farm construction in the Arctic region is faced with more technical problems than conventional attempts. For example, because the marine environment in the Arctic region is different from that in areas with low latitudes, the construction equipment, materials and techniques need to adapt to the cold climate in the Arctic region and the consequent restrictions, and difficulties such as long route, high costs of logistics, and ecological environment that is vulnerable to damage but difficult to restore have to be overcome. However, due to the large scale and complexity of wind farm construction, low temperatures, permafrost and the ecological environment, and the harsh construction conditions in the Arctic region, it is usually difficult to identify many project problems in the preliminary design phase.

Before and during the construction, different unforeseen difficulties should be recorded immediately with the progress of detailed survey, construction design and construction phases, as well as the implementation of supplementary investigation and accumulation of experience, and the construction program needs to be improved constantly.

Transportation in Construction of Offshore Wind Farms in Arctic Region.Offshore wind farms are under offshore complex environmental conditions and are affected by bad weather, as well as wind, wave and current. To ensure that fans are transported to the designated locations fast and safely, the technical parameters of engine rooms, hubs, blades, tower silos, bases and other parts of the fans and the transport equipment. Depending on the installation of different units, appropriate transport schemes should be specified. Offshore transportation is generally provided by the wind farm construction party, according to the contract requirement. Considering the large difficulty in offshore wind turbine assembly and the restriction of natural environment, lifting capacity and ship performance, in order to avoid risk and shorten the construction period, the transportation of offshore wind turbines should be matched with the lifting methods and is mainly divided into two methods: split transport and integral transport.

Foundation Construction in Building of Offshore Wind Farms in Arctic Region.The complex geological conditions in the Arctic region pose various environmental factors to consider, including low temperatures, freezing, blizzards, permafrost, and sea ice. Construction of offshore wind power in the Arctic region is subject to the impact of many factors and higher requirements on the foundation. It is not recommended to build wind farms in deeper waters of the Arctic region because in these areas there are large floating ices and glaciers whose impact can hardly be resisted by ordinary large buildings. Besides, the difficulty of construction in deep waters is greater. 
Full consideration should be given to sea ice, fundamental geology, ice conditions, and ship draft in the offshore wind turbine construction carried out in shallow waters in the Arctic region. Thus, depending on the special nature of the Arctic region, the foundations of offshore wind farms are not necessarily traditional, fixed, or single, they can be hybrid or newly developed foundation structures. Such foundations can reduce investment costs and increase security. Single-column and multi-pile foundations and multi-pile bearing structures should be the focus of investigation and research.

Wind Turbine Installation on Offshore Wind Farms in Arctic Region.Considering the geographical and geological characteristics and construction conditions in the Arctic region, wind turbine installation, if conducted offshore, is subject to higher technical requirements and the restrictions of climate, weather, wave, current, and sea ice. These factors are most difficult to control in the installation plan of offshore wind farms and the most important factors that limit the development of offshore wind farm in the Arctic region.

In the Arctic region, most of the construction process goes on only in certain seasons, and any mistakes in the offshore construction design and operation can result in schedule delays which have decisive impact on the whole project. According to the installation process, offshore wind farm installation is divided into two categories: split offshore installation and integral offshore installation. Corresponding to the installation methods, the transportation is divided into split offshore transportation and integral offshore transportation. Compared with split lifting, integral lifting is characterized by high lifting center of gravity, heavy mass, unstable lifting process and difficult safety control. However, as the fans have been pre-assembled on land or in near shore bases, all the operations can be finished in one-time lifting offshore to save offshore construction processes and reduce the time for offshore operations. Thus, the construction risks are reduced in environments where there are many uncontrollable factors in offshore construction.

Considering the characteristics of construction in the Arctic region and the service cost of workboats and by comparison of the two different installation methods, integral lifting would be more appropriate for fan installation during wind power construction in the Arctic region.

\section{Conclusion}

The wind farms in the Arctic region are still in the exploratory stage, and so far China has never tried any wind farm construction in the Arctic region. Due to the restrictions of climate and equipment, wind farm construction in the Arctic region is faced with more technical problems than conventional attempts. Due to the large scale and complexity of wind farm construction, low temperatures, permafrost and ecological environment, and the harsh construction conditions in the Arctic region, and lack of experience, it is usually difficult to identify many project problems in cold areas during the preliminary design phase.

Before and during the construction, different unforeseen difficulties should be recorded immediately with the progress of detailed survey, construction design and construction phases, as well as the implementation of supplementary investigation and accumulation of experience, and the construction program needs to be improved constantly.

\section{References}

1. JK Kaldellis, D Zafirakis. The influence of technical availability on the energy performance of wind farms: Overview of critical factors and development of a proxy prediction model, Journal of Wind Engineering \& Industrial Aerodynamics, 2013 
2. MA Mahar, AS Larik, MR Abro. Wind Power Performance Improvements Using Artificial Neural Network Controller for DC - DC Converter, Energy, Environment and Sustainable Development 2012

3. K Sobrink, D Woodford, R Belhomme. AC Cable versus DC Cable Transmission for" Offshore Wind Farms, a Study Case. International Workshop on Large-scale Integration of Wind Power \& Transmission Networks for Offshore Wind Farms - 2003

4. AJ Shi, J Thorp, R Thomas . An AC/DC/AC Interface Control Strategy to Improve Wind Energy Economics. IEEE Transactions on Power Apparatus \& Systems, 1986 